\title{
Minding our words
}

\author{
Kamran Abbasi international editor
}

The BMJ

We must choose our words carefully. Take Jeremy Hunt, for example. England's health secretary has earned a reputation for misrepresenting statistics on weekend mortality and exaggerating the effects of industrial action by doctors (doi:10.1136/bmj. h6358). Mindful of Hunt's scare tactics about the effects of reduced staffing, you might be surprised to learn that the NHS did not collapse after the junior doctors' strike on 12 January (doi:10.1136/bmj.i314).

As rational thinkers, we will withhold judgement on the effect of the strike on outcomes among patients, but as with previous one-off action any serious effect seems unlikely. In a scenario where the public reputation of junior doctors is untarnished, possibly enhanced, and patients are unaffected, the biggest blow—a "punch," some said — - was landed on Hunt's crusade against juniors.

Yet Hunt, who is suddenly "busting a gut" on behalf of patients, isn't alone in being careless with words and phrases. Stella Duffy explains her decision to opt for mastectomy and reconstructive surgery after a diagnosis of ductal carcinoma in situ (doi:10.1136/bmj.h6786). Her reasons for reconstructive surgery were well considered. Less so the reaction from health professionals. Duffy was repeatedly told, by virtual strangers, that her reconstructed breast "looked good." But her greater concern was how her reconstructed breast felt, how it was very different from what her breast felt like before, how it no longer felt like a breast, how nobody discussed this with her before her operation.
Simon Cocksedge, a Derbyshire GP, worries about words. He argues that describing patients as "heartsink" is derogatory and demeaning (doi:10.1136/bmj.h6542). The registrars at his practice and the multidisciplinary team are also opposed to its use. "How would you feel as the patient with that label?' said one. They were worried about the mindset it instils in a practitioner. Better to be interested in a patient and the challenges they pose.

Meanwhile our columnist David Oliver, a geriatrician, turns his attention to doctors who protest that they didn't "go into medicine to do social work" (doi:10.1136/bmj.i270). By social work they mean multidisciplinary rehabilitation and discharge planning for patients with complex comorbidities. This, he says, describes the job of geriatricians.

It is a job that requires dedication, skill, and judicious choice of words. All these attributes are also essential to win one of The BMJ Awards. Entries for this year are still open. For a chance to be recognised for your work visit thebmjawards.bmj. com/home.

1 Cooper C. Jeremy Hunt criticised over junior doctor fiasco-by his own chief negotiator. Independent 15 Jan 2016. www.independent.co.uk/life-style/health-and-families/healthnews/jeremy-hunt-criticised-over-junior-doctor-fiasco-by-his-own-chief-negotiatora6812521.html. 